\title{
Synthesis of agarose-metal/semiconductor nanoparticles having superior bacteriocidal activity and their simple conversion to metal-carbon composites ${ }^{\dagger}$
}

\author{
K K R DATTA ${ }^{\mathrm{a}}$, B SRINIVASAN ${ }^{\mathrm{b}}$, H BALARAM ${ }^{\mathrm{b}}$ and M ESWARAMOORTHY ${ }^{\mathrm{a} *}$ \\ ${ }^{a}$ Chemistry and Physics of Materials Unit and DST Unit on Nanoscience, \\ Jawaharlal Nehru Centre for Advanced Scientific Research, Jakkur PO, Bangalore 560064 \\ ${ }^{\mathrm{b}}$ Molecular Biology and Genetics Unit, Jawaharlal Nehru Centre for Advanced Scientific Research, \\ Jakkur PO, Bangalore 560064 \\ e-mail: eswar@jncasr.ac.in
}

\begin{abstract}
Agarose, a naturally occurring biopolymer is used for the stabilization of metal, semiconductor nanoparticles. Ag and $\mathrm{Cu}$ nanoparticles stabilized in agarose matrix show excellent antibacterial activity against $E$. coli bacteria. The well dispersed metal nanoparticles within the agarose composite films can be readily converted to carbon-metal composites of catalytic importance.
\end{abstract}

Keywords. Biopolymers; agarose-metal/semiconductor nanoparticle films; antimicrobial activity; composites; metallic.

\section{Introduction}

Research on polymer-metal nanoparticle composites received much attention in recent years owing to their application in opto-electronics, ${ }^{1}$ nonlinear optical devices $^{2}$ and colour filters. ${ }^{3}$ The size dependent electronic and optical properties of the nanoparticles coupled with the optical transparency and mechanical stability of the polymer films signify their importance in many applications. Among the wide variety of polymer matrices, biopolymers become the preferred choice as they are readily available, inexpensive, environmentally green and more amenable to scale up. Moreover, the oxygen rich functionalities of the biopolymers and their affinity towards metals make them ideal candidates for the stabilization of nanoparticles. ${ }^{4}$ Though biopolymers such as cellulose, ${ }^{5}$ starch, ${ }^{6}$ and alginic acid ${ }^{7}$ have been used for the stabilization of nanoparticles, another natural polymer in that series, agarose, has not been fully exploited despite its ability to form a transparent gel and films which can be used for packaging and separation purposes. Agarose is an oxygen rich naturally occurring polysaccharide extracted from seaweed. It consists of alternating 1,3-linked $\beta$-D-galactose and 1,4-linked 3,6 -anhydro- $\alpha$-L-galactose and is known for its gela-

${ }^{\dagger}$ Dedicated to Prof. C N R Rao on his 75th birthday

*For correspondence tion property, finds application in gel electrophoresis. ${ }^{8}$ Gel formation occurs when cooling the hot aqueous agarose solution to room temperature which is stable over a wide range of $\mathrm{pH}$ from 3 to 9. Caruso et $a l^{9}$ used the porous, agarose polymer matrix as a sacrificial template to prepare macroporous metal oxides. Kattumuri et $a l^{10}$ reduced the Au ions in presence of agarose matrix using trimeric alanine phosphine conjugates and used it for the surface-enhanced Raman spectroscopic detection of DNA nucleosides. Indeed, a general and simple route to make biopolymer-metal/semiconductor composite films would be advantageous given their potential application in many areas.

In this report, we have utilized the gel forming property of the agarose to make metal/semiconductor nanoparticles composite films by introducing the metal/semiconductor precursor solution followed by a reducing agent during the gelation process. The obtained metal-polymer composite was tested for its antimicrobial activity against Escherichia coli bacteria. The porous nature of the agarose polymer film coupled with antimicrobial silver and copper nanoparticles could find application in antimicrobial membrane filters as well as in antimicrobial coating. We have also demonstrated that well-dispersed metal nanoparticles on carbon matrix (Metal@C) can be prepared by carbonizing the metal-agarose composite film in a nitrogen atmosphere. 


\section{Experimental}

\subsection{Synthesis of metal nanoparticles-agarose composite}

Agarose stabilized metal nanoparticles were prepared by introducing the metal precursors in the aqueous solution of agarose. In a typical synthesis, $0.1 \mathrm{~g}$ of agarose (Type I) powder was added to a $10 \mathrm{~mL}$ of Milli-Q ${ }^{\mathrm{TM}}$ (Millipore, USA) purified water kept at $80^{\circ} \mathrm{C}$ with constant stirring. After 2 min a clear viscous solution was obtained. To this, $1 \mathrm{~mL}$ of $1 \mathrm{mM} \mathrm{AgNO}$ solution was added followed by $200 \mu \mathrm{l}$ of $10 \mathrm{mM} \mathrm{NaBH}_{4}$ solution. The resulting yellow coloured, transparent solution is indicative of the formation of $\mathrm{Ag}$ nanoparticles. On cooling to room temperature a yellow coloured, transparent gel was obtained which was then transformed to a transparent, yellow colour film on drying. Similar procedure was repeated for the synthesis of $\mathrm{Au}, \mathrm{Pt}$ and $\mathrm{Pd}$ nanoparticles. $\mathrm{HAuCl}_{4}, \mathrm{H}_{2} \mathrm{PtCl}_{6}$ and $\mathrm{PdCl}_{2}$ were chosen as metal precursors. Correspondingly, we obtained red, light brown, brown, film for $\mathrm{Au}, \mathrm{Pt}$ and $\mathrm{Pd}$ nanoparticles loaded agarose composites. For copper-agarose composite, $1 \mathrm{~mL}$ of $10 \mathrm{mM} \mathrm{CuSO}_{4}$ solution was reduced with $500 \mu \mathrm{l}$ of $1 \mathrm{M} \mathrm{N}_{2} \mathrm{H}_{4}$ hydrate solution. The evolution of nitrogen when $\mathrm{N}_{2} \mathrm{H}_{4}$ was used as the reducing agent provides an inert environment that stabilizes the copper nanoparticles in the agarose matrix for a longer period of time against immediate air oxidation.

\subsection{Synthesis of semi-conducting nanoparticles- agarose composite}

For the synthesis of $\mathrm{CdS}, \mathrm{PbS}$ and $\mathrm{ZnS}$-agarose composite films, $\mathrm{Cd}\left(\mathrm{NO}_{3}\right)_{2}, \mathrm{~Pb}\left(\mathrm{NO}_{3}\right)_{2}$, and $\mathrm{Zn}\left(\mathrm{NO}_{3}\right)_{2}$ were used as the metal precursors. $\mathrm{Na}_{2} \mathrm{~S}$ was taken as the sulphide precursor. To the $10 \mathrm{~mL}$ of Milli-Q water kept at $80^{\circ} \mathrm{C}, 0 \cdot 1 \mathrm{~g}$ of agarose (Type I) powder was added with constant stirring until it dissolves. To this solution $500 \mu \mathrm{l}$ of $0 \cdot 1 \mathrm{M}$ metal nitrate was added followed by the equal volume of $0 \cdot 1 \mathrm{M} \mathrm{Na}_{2} \mathrm{~S}$. The clear mixture was then cooled to room temperature to obtain the semiconductor nanoparticle incorporated agarose gel which was then converted into a film on drying at room temp.

\subsection{Synthesis of LB-agarose-nanoparticles (Ag or Cu) composites for assessment of antibacterial activity}

A slight modification of the protocol for the synthesis of nanoparticles was done to assess their antibac- terial activity. The nanoparticles were synthesized in Luria-Bertani (LB) medium rather than in Milli-Q purified water. All apparatus used for nanoparticle film preparation were autoclaved prior to use. All reactions were performed in a laminar hood, with high efficiency particulate air filter system, to ensure sterility. LB broth was prepared by addition of $0.5 \mathrm{~g}$ of yeast extract, $1 \mathrm{~g}$ of Type I casein enzyme hydrolysate, $1 \mathrm{~g}$ of sodium chloride and $20 \mu \mathrm{l}$ of $5 \mathrm{~N} \mathrm{NaOH}$ to $100 \mathrm{~mL}$ of distilled water.

$0.1 \mathrm{~g}$ agarose (Type I) was dissolved in a $10 \mathrm{~mL}$ of LB broth kept at $80^{\circ} \mathrm{C}$ with constant stirring. To this $50 \mu \mathrm{L}$ of $0.01 \mathrm{M} \mathrm{AgNO}_{3}$ (about $5 \mu \mathrm{g}$ of $\mathrm{Ag}$ per $\mathrm{mL}$ of LB broth) was added followed by the addition of $10 \mu \mathrm{L}$ of $0.1 \mathrm{M} \mathrm{NaBH}_{4}$ solution. A dark orange colour appears within $5 \mathrm{~min}$ due to the formation of Ag nanoparticles that becomes faint upon solidification and gets masked due to the components of LB broth. Another batch containing higher concentration of silver nanoparticles (about $10 \mu \mathrm{g}$ of $\mathrm{Ag}$ per $\mathrm{mL}$ of LB broth) was also prepared by adding $100 \mu \mathrm{L}$ $0.01 \mathrm{M} \mathrm{AgNO}_{3}$ solution followed by the addition of $25 \mu \mathrm{L}$ of $0 \cdot 1 \mathrm{M} \mathrm{NaBH}_{4}$. The same protocol was used to synthesize agarose composite gels containing copper nanoparticles (from copper sulphate precursor) at two different concentrations(about $3 \mu \mathrm{g}$ and $6 \mu \mathrm{g}$ of $\mathrm{Cu}$ per $\mathrm{mL}$ of $\mathrm{LB}$ broth) using hydrazine hydrate as the reducing agent. Immediate appearance of wine red colour was observed indicating the formation of copper nanoparticles which becomes faint upon solidification and gets masked due to the components of LB broth. The nanoparticles were trapped in the LB agarose matrix, which were then employed to check the antibacterial activity without further modification. The plates, with the nanoparticles embedded in the matrix, were left aside for $45 \mathrm{~min}$ before plating bacteria. The $\mathrm{pH}$ of the various solutions was maintained at 7 to rule out the possibility of bacterial growth inhibition due to $\mathrm{pH}$ effect.

\subsection{Analysis of antibacterial activity of $L B$ - agarose containing silver and copper nanoparticles}

Glycerol stock of E. coli strain $\mathrm{DH} 5 \alpha$, stored at $-80^{\circ} \mathrm{C}$, was inoculated in $5 \mathrm{~mL}$ of Luria-Bertani (LB) broth and allowed to grow for $12 \mathrm{~h}$ at $37^{\circ} \mathrm{C}$ in a shaker incubator. The grown bacterial cells were reinoculated into $10 \mathrm{~mL}$ of fresh LB broth and allowed to grow till the Optical density reached 1.0 at $600 \mathrm{~nm}$. Bacterial cells were harvested by centrifugation at $6000 \mathrm{rpm}$ for $15 \mathrm{~min}$ and resuspended in $200 \mu \mathrm{L} \mathrm{LB}$ 
broth. The resuspended bacteria were spread onto LB agar plates containing varied concentrations of silver and copper nanoparticles. The spread plated LB agar plates were incubated at $37^{\circ} \mathrm{C}$ for $12 \mathrm{~h}$. Appropriate control experiments were included to rule out the possibility of other components being antibacterial.

\subsection{Synthesis of carbon-metal nanoparticles composites}

To obtain the carbon-metal nanoparticles composites, the agarose-metal nanoparticles composite films were carbonized in an inert atmosphere (nitrogen gas) at $400^{\circ} \mathrm{C}$ for $30 \mathrm{~min}$ and then slowly cooled to room temperature.

\subsection{Characterization techniques}

The agarose-metal nanoparticle composite film was probe sonicated for $2 \mathrm{~min}$ in ethanol. The obtained dispersion was drop casted on a carbon-coated copper grid. TEM images were recorded with a JEOL JEM 3010 instrument (Japan) operated at an accelerating voltage of $300 \mathrm{kV}$.

The dispersion of metal nanoparticles embedded inside carbon matrix was examined by a Field Emission Scanning Electron Microscope (FESEM, FEI Nova-Nano SEM-600, Netherlands).

The films obtained after drying agarose-nanoparticle gel were checked for UV-Vis absorption measurements. UV-Vis absorption spectroscopic measurements were performed with Perkin-Elmer instruments Lambda $900 \mathrm{UV} / \mathrm{Vis} / \mathrm{NIR}$ spectrometer.

Photoluminescence studies were done by using Perkin Elmer LS 50B instrument using a Xe lamp source.

\section{Results and discussion}

The optical images of the transparent, agarosestabilized metal nanoparticles gels are shown in Figure 1a. It shows a light brown colour for $\mathrm{Pt}$ and $\mathrm{Pd}$, turmeric yellow for $\mathrm{Ag}$, bright red for $\mathrm{Au}$ and a wine red colour for $\mathrm{Cu}$ nanoparticles stabilized by agarose polymer. Prolonged drying for $48 \mathrm{~h}$ at room temperature allows these gels to become transparent composite films with a slight reduction in the intensity of the original colours (figure S1 in Supporting Information). In the case of agarose-copper composite gel, the wine red colour slowly transformed to pale green on drying due to partial oxidation of cop- per in air. The UV-Vis spectra of the dried films show plasmonic bands in the visible region at 420 , 520 and $585 \mathrm{~nm}$ respectively for $\mathrm{Ag}, \mathrm{Au}$ and $\mathrm{Cu}$ nanoparticles loaded composites (figure $1 b$ ). On the other hand, the $\mathrm{Pt}$ and $\mathrm{Pd}$ nanoparticles composite films do not show any sharp plasmon band and the absorption is spread over the entire visible region. ${ }^{11}$

The fine dispersion of metal nanoparticles throughout the agarose matrix is evident from the transmission electron microscopic (TEM) images of the composite films shown in figure 2 . The agarose matrix that appears in light contrast in comparison to the electron dense metal nanoparticles is highly porous in nature and the sizes of the macropores are in the range of 50 to $200 \mathrm{~nm}$. Au and $\mathrm{Ag}$ nanoparticles of sizes less than $10 \mathrm{~nm}$ are well dispersed inside the agarose matrix. Occasionally, few silver nanoparticles of size around $30 \mathrm{~nm}$ are seen in the larger pores of agarose network. In the case of copper, the particles size fall far below $5 \mathrm{~nm}$ and are evenly distributed in the agarose network seen from the uniform dark contrast in the TEM image. These findings suggest that the presence of functional groups such as hydroxyl and ether linkages in the agarose network

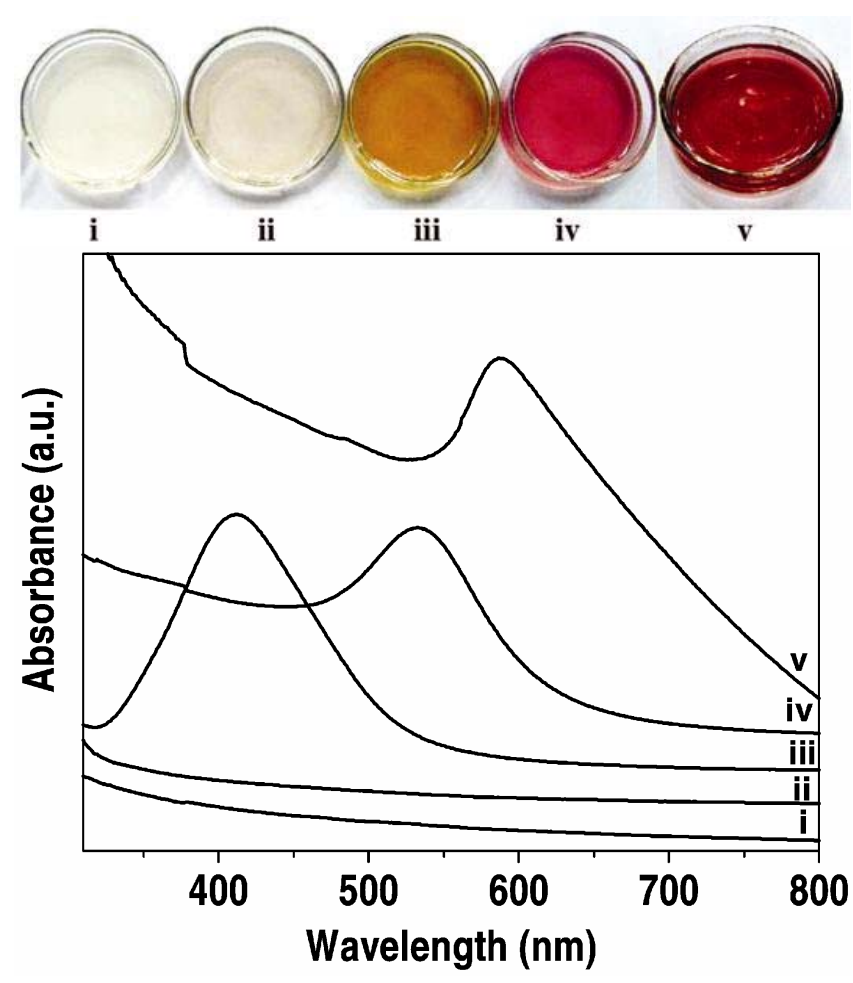

Figure 1. (a) Optical images of agarose-metal nanoparticles composites (i) Pd, (ii) Pt, (iii) Ag, (iv) Au and (v) $\mathrm{Cu}$ nanoparticles in agarose matrix and (b), Corresponding UV-Vis absorption spectra. 


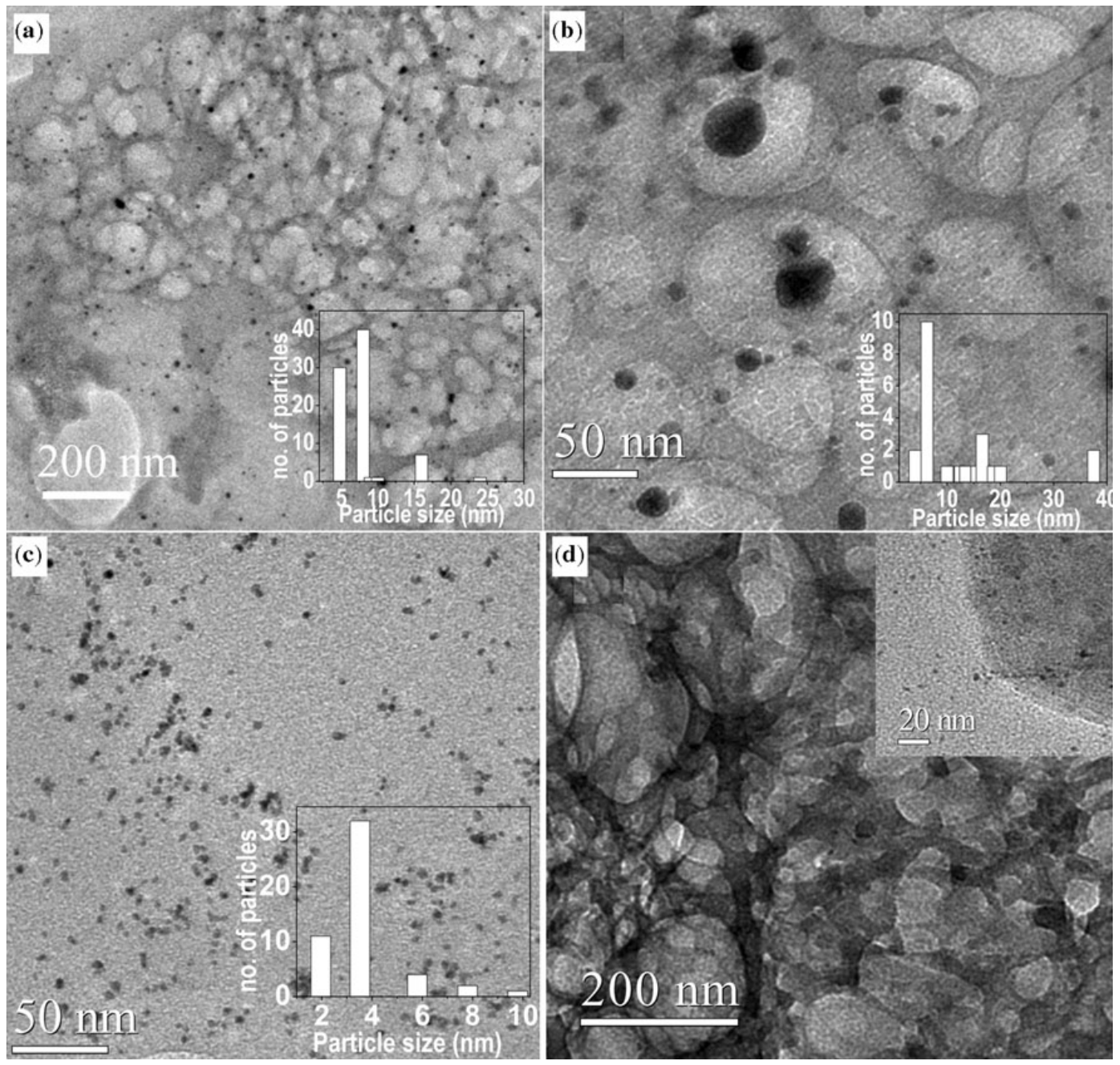

Figure 2. TEM images of (a) $\mathrm{Au}$, (b) $\mathrm{Ag}$, (c) $\mathrm{Pt}$, and (d) $\mathrm{Cu}$ nanoparticles in agarose matrix. Insets in images $(\mathbf{a}-\mathbf{c})$ show the histogram of particle size distribution of corresponding nanoparticles, the inset in image (d) shows the higher magnification image of $\mathrm{Cu}$ nanoparticles.

effectively help in passivating the surface of nanoparticles. Interestingly, reduction of $\mathrm{Ag}$ and $\mathrm{Au}$ ions using glucose within the agarose medium gives bright yellow and violet coloured Ag-, and $\mathrm{Au}-$ agarose composites (figure $3 \mathrm{a}$ ). The corresponding plasmon bands in the UV-Vis spectra shifted to longer wavelengths (nearly $30 \mathrm{~nm}$, figure $3 \mathrm{~b}$ ) compared to the composites prepared using sodium borohydride as the reducing agent. This shift in the plasmon band for higher wavelength is associated with the larger particle sizes obtained by the slow diffusion of reducing agent, glucose, compared to $\mathrm{NaBH}_{4}$ inside the agarose matrix.

The gel forming ability and the oxygen-based functional groups of agarose polymer are not only used to stabilize metal nanoparticles but also the semiconducting metal sulphide nanoparticles. The optical image of the semiconducting $\mathrm{PbS}, \mathrm{CdS}$ and $\mathrm{ZnS}$ nanoparticles encapsulated in agarose matrix is shown in figure $3 \mathrm{c}$. The $\mathrm{CdS}$ and $\mathrm{PdS}$ nanoparticles impart yellow and dark-brown colours respectively to the agarose matrix whereas, the $\mathrm{ZnS}$ nanoparticle impart no colour to the gel. The transparent nature of the composite films confirms the presence of metal sulphide particles in the nanosize regime. The UV-Vis absorption spectra of the agarose-semiconductor nanoparicles composites are shown in figure $3 \mathrm{~d}$. The CdS-agarose composite film obtained after drying the gel in air at $30^{\circ} \mathrm{C}$ shows a characteristic absorption band edge at around $450 \mathrm{~nm} .^{12}$ The $\mathrm{PbS}$-agarose composite film also shows a broad absorption all through the visible region in addition to a strong absorption below $380 \mathrm{~nm}$. On the other hand, $\mathrm{ZnS}$-agarose composite did not show any ab- 
(a)

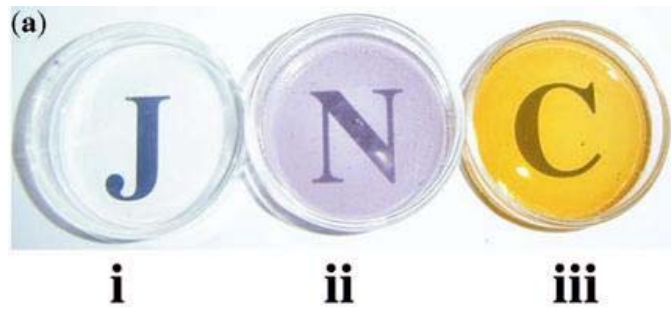

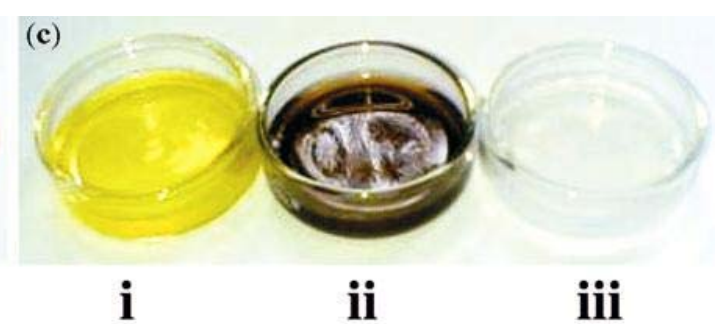
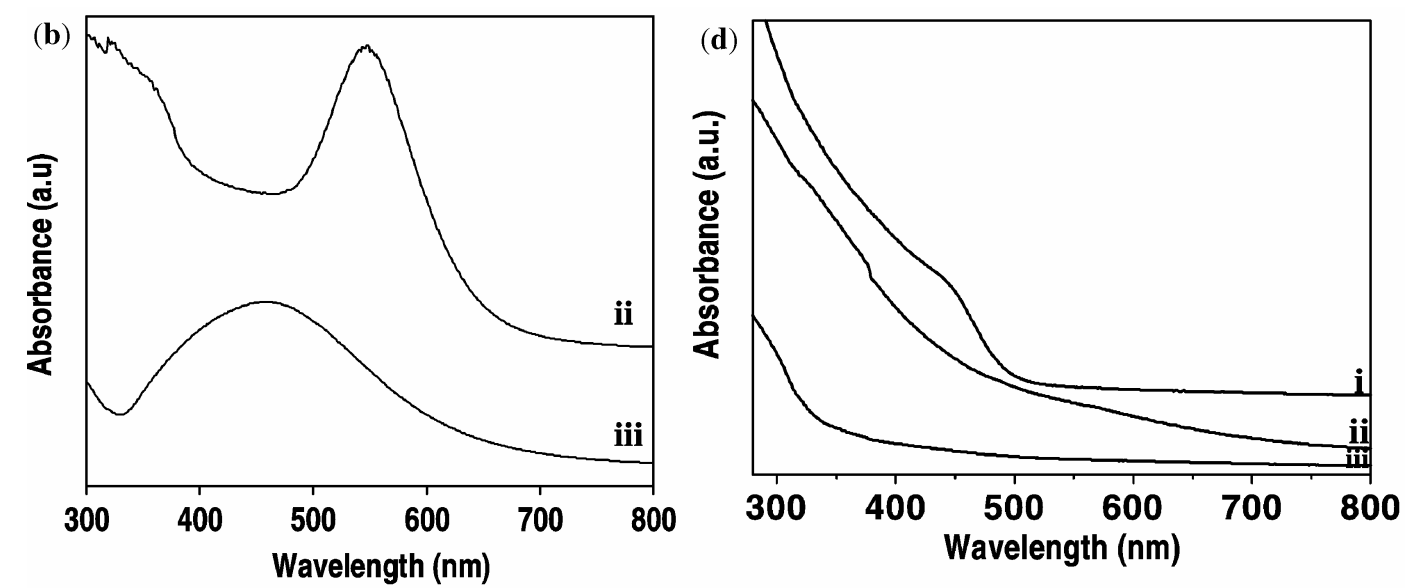

Figure 3. (a) Optical images of (i) Agarose gel, (ii) Au nanoparticles in agarose, and (iii) Ag nanoparticles in agarose and (b), corresponding UV-Vis absorption spectra. (c) Optical images of (i) $\mathrm{CdS}$, (ii) $\mathrm{PbS}$, and (iii) $\mathrm{ZnS}$ nanoparticles in agarose matix and (d), corresponding UVVis absorption spectra.

sorption in the visible region but only in the UV region below $320 \mathrm{~nm}$. The photoluminescence spectrum of the CdS-agarose film (CdS particle size around $2 \mathrm{~nm}$, TEM image is not shown) excited at 350 to $400 \mathrm{~nm}$ shows a broad yellow-orange emission with the peak maximum at $580 \mathrm{~nm}$ associated with the $\mathrm{CdS}$ nanoparticles (figure S2 in the Supporting Information). In case of $\mathrm{ZnS}$-agarose film, excitation at $300 \mathrm{~nm}$ resulted in blue emission at $435 \mathrm{~nm}$ (figure S3 in the Supporting Information). The transparent nature of the agarose-metal sulphide composite films coupled with their strong absorption in the UV and visible region would find application in UV and colour filters.

The antibacterial activity of silver and copper nanoparticles in the agarose matrix was tested on the bacteria $E$. coli. The antibacterial activity of silver nanoparticles is attributed to the increased chemical reactivity owing to their higher surface area to volume ratio. ${ }^{13}$ The changes in the local electronic structure on the surfaces of the smaller sized particles leads to the enhancement of their chemical reactivity leading to bactericidal effect. ${ }^{14}$ Various mechanisms, through which silver nanoparticles kill bacteria, have been proposed. They are known to destabilize the plasma membrane potential leading to the depletion in the levels of intracellular ATP bringing about cell death. They are also known to act through the formation of complexes with biomolecules containing sulfur, oxygen and nitrogen, such as thiols, carboxylates, amides, imidazoles, indoles and hydroxylates in proteins. ${ }^{15}$ Silver nanoparticles are also shown to display affinity towards phosphorous containing compounds. Peroxide and free radical generation by silver nanoparticles is yet another mode by which they kill bacteria. ${ }^{16}$ The excellent property of conformational entropy displayed by silver nanoparticles in polyvalent binding makes it easier for them to attach to flexible polymeric chains. ${ }^{17}$ These observations assume significance in the light of the increasing antibiotic resistance displayed by bacteria. Similarly, copper ions, either alone or in copper complexes, are known as antimicrobial agents. ${ }^{18-21}$ However, there are only a few reports on the antibacterial activity of copper nanoparticles. ${ }^{22-25}$

This study utilizes the E. coli strain DH5 $\alpha$ for checking the antibacterial action of silver and copper 
nanoparticles dispersed in the porous agarose matrix. E. coli is a gram negative, facultative anaerobic, non-sporulating, motile, rod shaped bacterium commonly found in the lower intestine of warmblooded animals. Figure 4 shows the antibacterial potency of silver and copper nanoparticles at two different concentrations stabilized by LB-agarose.

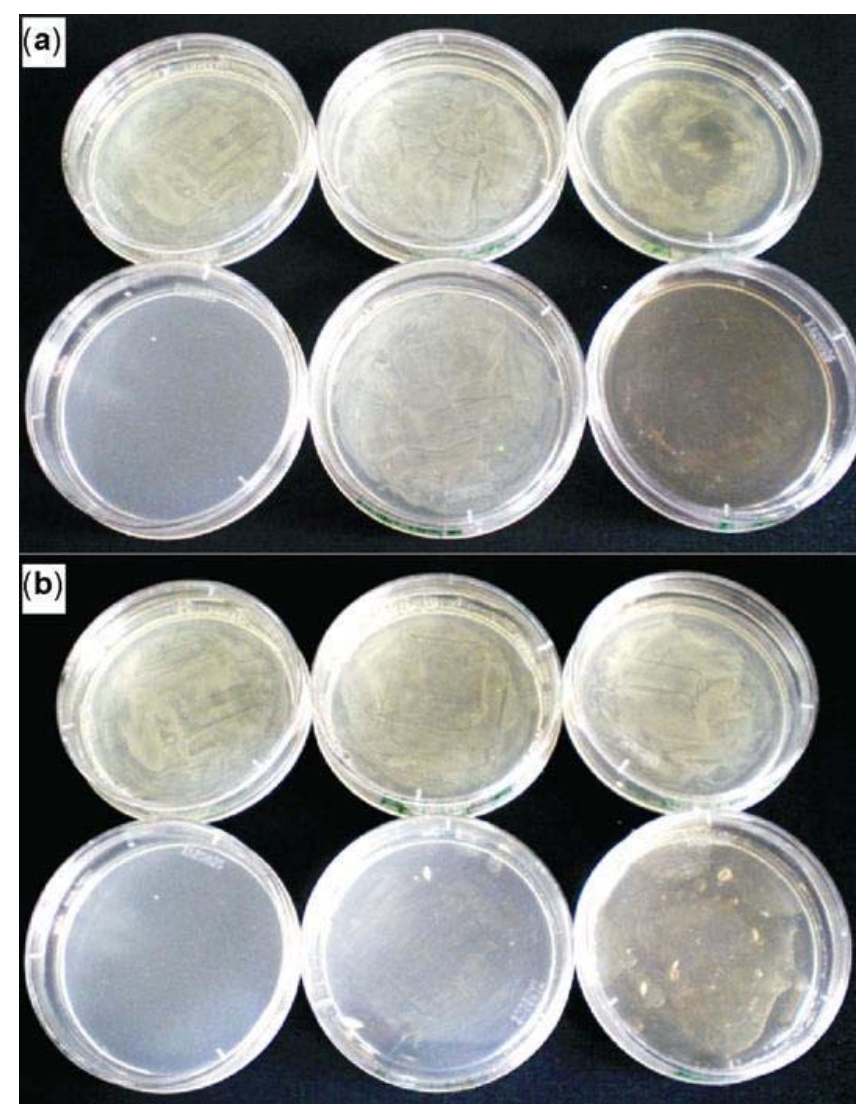

Figure 4. Antibacterial activity assay for silver and copper nanoparticles. The nanoparticles were synthesized in LB agarose and the bacteria were plated on them. Note that at higher concentration of $\mathrm{Ag}$ and $\mathrm{Cu}$ nanoparticles the colour of the gel gets little darker. (a) Upper left, agarose gel and bacteria; Upper middle, agarose gel with $\mathrm{NaBH}_{4}$ and bacteria; Upper right, agarose gel with silver nitrate and bacteria; Bottom left, agarose gel without bacterial inoculation; Bottom middle, agarose gel containing low concentration of $\mathrm{Ag}$ nanoparticles (about $5 \mu \mathrm{g}$ of $\mathrm{Ag}$ per gram of gel) and bacteria; Bottom right, agarose gel containing high concentration of silver nanoparticles (about $10 \mu \mathrm{g}$ of $\mathrm{Ag}$ per gram of gel) and bacteria. (b) Upper left, agarose gel and bacteria; Upper middle, agarose gel with hydrazine hydrate and bacteria; Upper right, agarose gel with copper sulphate and bacteria; Bottom left, agarose gel without bacterial inoculation; Bottom middle, agarose gel with low concentration of $\mathrm{Cu}$ nanoprticles (about $3 \mu \mathrm{g}$ of $\mathrm{Cu}$ per gram of gel) and bacteria; Bottom right, agarose gel with high concentration of $\mathrm{Cu}$ nanoprticles (about $6 \mu \mathrm{g}$ of $\mathrm{Cu}$ per gram of gel) and bacteria.
Both silver and copper nanoparticles showed effective inhibition as shown in the figures $4 a$ and $b$. Two types of bacterial inhibition, viz. bacteriocidal or bacteriostatic, are known to be caused by the application of nanoparticles on bacterial cultures. In bacteriocidal effect, the nanoparticles kill the bacteria and hence, prevent their growth in any fresh medium whereas, in bacteriostatic effect, they keep the bacteria dormant, giving room for their resuscitation in a suitable medium. In our case, both $\mathrm{Ag}$ and $\mathrm{Cu}$ nanoparticles show complete bacteriocidal effect as seen when the surface of the LB agar plate was scarped and restreaked onto a fresh plate, without nanoparticles, after three days. The absence of any colony growth on restreaking confirms the bacteriocidal effect of the $\mathrm{Ag}$ and $\mathrm{Cu}$ nanoparticles. The LB/agarose stabilized silver nanoparticles prepared with lower concentration of silver (about $5 \mu \mathrm{g}$ of $\mathrm{Ag}$ per gram of composite gel) showed nearly $50 \%$ inhibition of bacterial growth while doubling the concentration (about $10 \mu \mathrm{g}$ of $\mathrm{Ag}$ per gram of composite gel) displayed complete inhibition (figure $4 a$ ). In the case of copper, complete inhibition was observed even at lower concentration (at about $3 \mu \mathrm{g}$ of $\mathrm{Cu}$ per gram of composite gel) indicating the superior bacteriocidal activity of copper nanoparticles over silver nanoparticles (figure 4b). This is particularly significant when we compare the concentration of $\mathrm{Ag}$ nanoparticles used in other studies. For example, Kumar $e a^{26}$ used nearly $3000 \mu \mathrm{g}$ of Ag (in the form of nanoparticles) per gram of alkyd paint and $4000 \mu \mathrm{g}$ of $\mathrm{Au}$ (in the form of nanoparticles) per $\mathrm{mL}$ of vegetable oil for antimicrobial coatings. Similarly, Morones et $a l^{13}$ reported silver nanoparticles solution containing $75 \mu \mathrm{g}$ of $\mathrm{Ag} / \mathrm{mL}$ showing good antimicrobial activity. Silver nanoparticles of size less than $15 \mathrm{~nm}$ are known to have effective bactericidal activity ${ }^{13,27-29}$ contributed by $\mathrm{Ag}^{+}$and $\mathrm{Ag}^{0}$. The agarose matrix in our study plays a dual role for the exhibition of high antibacterial activity of nanoparticles even at very low metal concentration. It not only helps to stabilize the $\mathrm{Ag}$ and $\mathrm{Cu}$ nanoparticles of very small sizes by their functional $\mathrm{OH}$ groups but also facilitate the full exposure of these nanoparticles to the microorganism due to their large porous network.

\section{Conclusions}

In conclusion, transparent agarose-metal/semiconducting nanoparticle composite films were made 

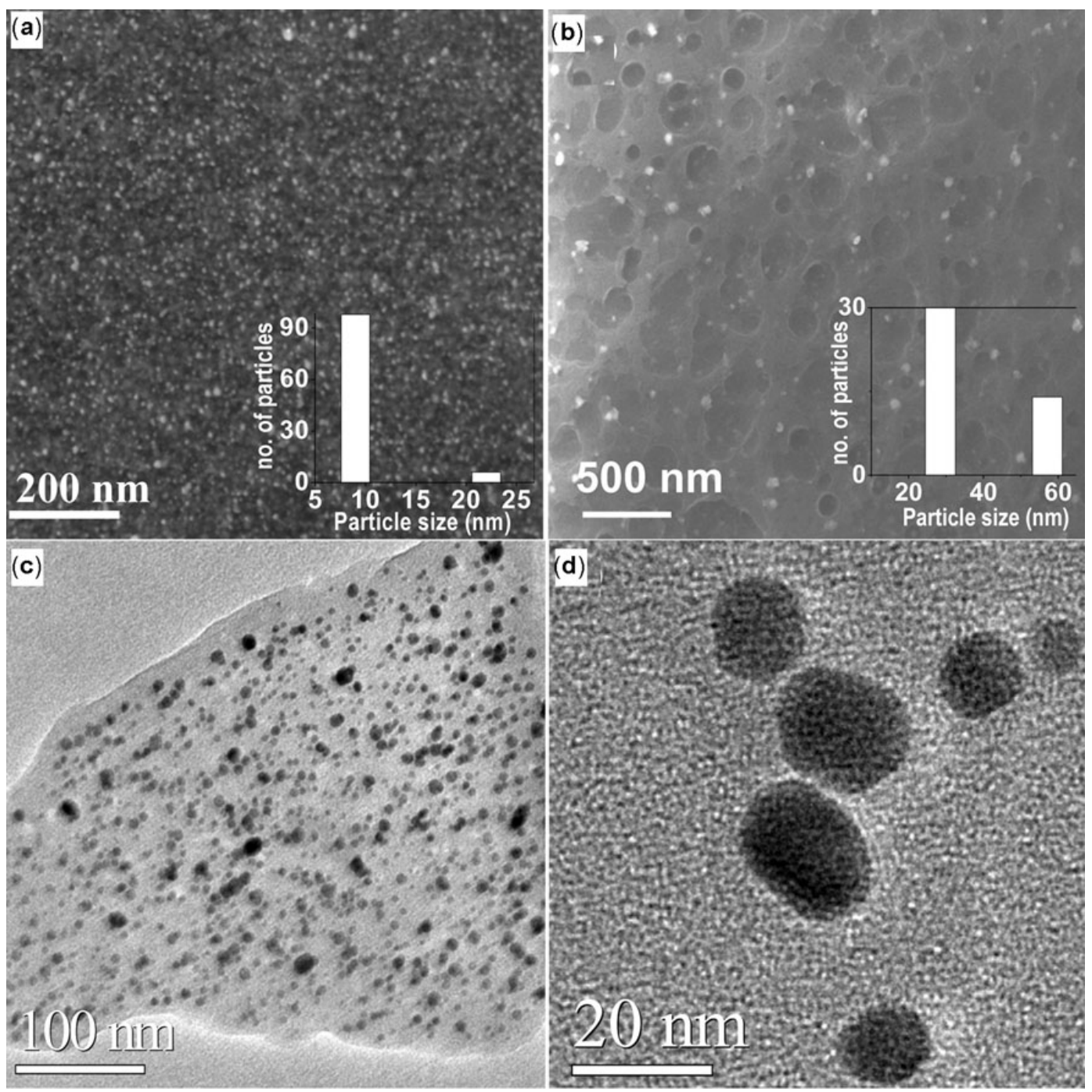

Figure 5. Field-emission scanning electron microscopic (FESEM) images of (a) Au- and (b) Ag-carbon composites after carbonization. TEM images of (c) Au- and (d) Ag-carbon composites. (a-b) Insets show the particle size histogram of corresponding nanoparticles inside the carbon matrix.

by a simple route without compromising the optical properties of the nanoparticles. The high level antimicrobial activity of the $\mathrm{Ag}$ and $\mathrm{Cu}$ nanoparticles stabilized in the porous agarose matrix can be utilized in food packaging, sanitation and fabrics. More importantly, the agarose-metal nanoparticles films can be readily converted into carbon-metal nanoparticles composites by carbonizing the films in nitrogen environment at $400^{\circ} \mathrm{C}$ for $30 \mathrm{~min}$. The obtained composites show fine distribution of metal nanoparticles (average particles size of $9 \mathrm{~nm}$ and $30 \mathrm{~nm}$ for $\mathrm{Au}$ and $\mathrm{Ag}$ respectively, figure 5) on carbon matrix whose applications in catalysis are well known. ${ }^{30}$

\section{References}

1. Korchev S, Bozack M J, Slaten B L and Mills G 2004 J. Am. Chem. Soc. 12610

2. Inouye $\mathrm{H}$, Tanaka $\mathrm{K}$, Tanahashi I, Hattori $\mathrm{T}$ and Nakatsuka H 2000 Jpn. J. Appl. Phys. 395132

3. Dirix Y, Bastiaansen C, Caseri W and Smith P 1999 Adv. Mater. 11223

4. Liu J C, He F, Durham E, Zhao D and Roberts C B 2008 Langmuir. 24328

5. He J, Kunitake T and Nakao A 2003 Chem. Mater. 15 4401

6. Raveendran P, Fu J and Wallen S L $2003 \mathrm{~J} . \mathrm{Am}$. Chem. Soc. 12513940

7. Brayner R, Vaulay M-J, Fiévet F and Coradin T 2007 Chem. Mater. 191190 
8. Serwer P 1983 Electrophoresis 4375

9. Zhou J, Zhou M and Caruso R A 2006 Langmuir 22 3332

10. Kattumuri V, Chandrasekhar M, Guha S, Raghuraman K, Katti K V, Ghosh K and Patel R J 2006 Appl. Phys. Lett. 88153114

11. Datta K K R, Eswaramoorthy M and Rao C N R 2007 J. Mater. Chem. 17613

12. Fan D, Thomas P J and Brien P O' 2007 J. Mater. Chem. 171381

13. Morones J R, Elechiguerra J L, Camacho A, Holt K, Kouri J B, Ramrez J T and Yacaman M J 2005 Nanotechnology 162346

14. Thiel J, Pakstis L, Buzby S, Raffi M, Ni C, Pochan D J and Shah S I 2007 Small 3799

15. Zeng F, Hou C, Wu S, Liu X, Tong Z and Yu S 2007 Nanotechnology 18055605

16. Kim J S, Kuk E, Yu K N, Kim J-H, Park S J, Lee H J, Kim S H, Park Y K, Park Y H, Hwang C-Y, Kim Y-K, Lee Y-S, Jeong D H and Cho M-H 2007 Nanomedicine: Nanotechnol., Biol. Med. 395

17. Li P, Li J, Wu C, Wu Q and Li J 2005 Nanotechnology. 161912

18. Gadi B and Jeffrey G 2005 Curr. Med. Chem. 122163

19. Gadi B and Jeffrey G 2004 The FASEB Journal Express
20. Faúndez G, Troncoso M, Navarrete P and Figueroa G 2004 BMC Microbiol. 419

21. Trapalis C C, Kokkoris M, Perdikakis G and Kordas G 2004 J. Sol-Gel Sci. Technol. 261213

22. Yoon K-Y, Byeon J H, Park J-H and Hwang J 2007 Sci. Total Environ. 373572

23. Cioffi N, Ditaranto N, Torsi L, Picca R A, Giglio E D, Sabbatini L, Novello L, Tantillo G, Bleve-Zacheo T and Zambonin P G 2005 Anal. Bioanal. Chem. 382 1912

24. Gu C, Sun B, Wu W, Wang F and Zhu M 2007 Macromol. Symp. 254160

25. Qi L, Xu Z, Jiang X, Hu C and Zou X 2004 Carbohydrate Res. 3392693

26. Kumar A, Vemula P K, Ajayan P M and John G 2008 Nature Mater. 7236

27. Sudhir K 1998 Langmuir. 141021

28. Kumar G S, Gopinath P, Anumita P, Ramesh, A, Ghosh S S and Chattopadhyay A 2006 Langmuir. 22 9322

29. Pallab S, Murugadoss A, Prasad P V D, Ghosh S S and Chattopadhyay A 2008 Int. J. Food Microbiol. 124142

30. Dhas N A, Cohen H and Gedanken A 1997 J. Phys. Chem. B101 6834 